\title{
Peasant farmer behavior and cereal technologies: Stochastic programming analysis in Niger
}

\author{
Akinwumi A. Adesina ${ }^{l}$ and John H. Sanders ${ }^{2}$ \\ IInternational Crops Research Institute for the Semi-arid Tropics (ICRISAT), B.P. 320, Bamako (Mali) \\ ${ }^{2}$ Department of Agricultural Economics, Purdue University, West-Lafayette, IN 47907 (U.S.A.)
}

(Accepted 2 March 1990)

\begin{abstract}
Adesina, A.A. and Sanders, J.H., 1991. Peasant farmer-behavior and cereal technologies: Stochastic programming analysis in Niger. Agric. Econ., 5: 21-38.

Peasant farmers in Sahelian West Africa adjust to rainfall uncertainties in the agricultural season by making decisions sequentially as a function of the evolving rainfall patterns. Understanding such flexibilities in farmer decision-making is central to technology introdiction. Thï paper determines how sequential decision-making under weather uncertainty affects the adoption and farm-level effects of cereal technologies in Niger. The study also draws policy implications for a price floor to arrest the substantial fall in cereal prices in good rainfall years when farmers have more grains to sell. The methodology used is Discrete Stochastic Programming. This paper shows that the ability of peasant farmers to adapt cropping and resource-management strategies to the rainfall patterns is the basis for their survival in this highrisk environment. Model results show that by (a) carrying a portfolio mix of varieties of varying maturities, and (b) making sequential decisions based upon rainfall expectations, farmers can adapt to the production uncertainties. Breeding programs should therefore be diversified to develop not only early-maturing cultivars, but also improved intermediate and long-season varieties.
\end{abstract}

\section{Introduction}

The problem of low agricultural output in semi-arid West Africa (WASAT) and the technical alternatives to arrest the trend has been extensively discussed in recent times (Matlon, 1987; Nagy et al., 1988; Sanders, 1989). However, adoption rates of many introduced technologies have been low (Spencer, 1985; Starkey, 1986). While technical limitation of introduced technologies is often highlighted as the factor limiting adoption, the role of small-farmer decision-making as it affects choices of crop varieties and other technologies has been ignored. Agricultural development programs in WASAT need to consider the implications of farmer decision making strategies for technology choices. Arguments have been made of the need for 
better understanding of how this human element influences the choice and the farm-level effects of agricultural technologies (Norman et al:, 1981; Spencer, 1985).

In Sahelian West Africa, where extreme weather and price uncertainties characterise agriculture, farmers have developed strategies to cope with the high-risk levels of rainfed agriculture. One such strategy is to make sequential and adaptive decisions in response to the ensuing rainfall patterns in the crop season. In northern Nigeria, peasant farmers have been observed to change choice of plant populations, fertiliser and crop management techniques in the crop season based upon rainfall expectations (Balcet and Candler, 1981). These expectations are often revised as the crop season progresses. Similar farmer behavior has been observed in Niger (Unité Suivi d'Evaluation, 1986) and Burkina-Faso (Kristjanson, 1987). Earlier studies on technology adoption in Sahelian West Africa have not considered the implications of these weather-responsive decision-making strategies for technology choices (Jaeger, 1984; Adesina et al., 1988; Niang, 1980). While Kristjanson (1987) used an econometric model to look at relationships between exogenously defined rainfall variables and crop yields, the study did not consider how sequential decision-making in the whole-farm context affects choices of technologies. Also, the study did not consider how farmer resource-use patterns, livestock sales patterns, and-grain purehase-strategies (to satisfy household grain needs) are altered in response to rainfall uncertainties. Village-level studies have shown these elements as important in farmer-adaptive strategies (Reardon et al., 1988; Swinton, 1988).

The objective of this paper is to evaluate how sequential decision-making under conditions of uncertainty affects the adoption and the farm-level effects of cereal technologies in Niger. The paper also investigates the implications of cereal price floors to arrest the precipitous cereal-price collapses that frequently occur in Niger during good rainfall years. The analysis carried out within a whole-farm context, and over alternative rainfall scenarios, provides a more comprehensive assessment of the potential adoption patterns of cereal technologies.

\section{Cereal technologies in Niger}

Farmers in Niger are predominantly millet and cowpeas producers. Although sorghum is also important in Niger, it is concentrated in the southern portion of the country characterised by higher rainfalls and heavier soils. Millet is widely grown due to its ability to grow under limited water conditions and on poor soils on which sorghum would not adapt. Cowpeas are cropped in associations with cereals, at low planting densities. Cropimprovement programs in Niger have directed major efforts to development 
of appropriate cultivars and technology packages for the millet/cowpea cropping systems. The national program has had some success developing new cultivars and improved agronomic practices for this association (Reddy, 1988); these have been proposed to farmers in different agro-ecological zones. For the higher-rainfall southern zones (especially the Maradi region), the most recommended combinations are millet variety CIVT and cowpea variety $\mathrm{TN} 5-78$. These improved and early-maturing varieties can play an important role in allowing farmers flexibility in cropping decisions. The local varieties planted by farmers are late-maturing and yield poorly in lowrainfall years with short growing-seasons. Farmers have therefore been advised to adopt early-maturing varieties to avoid these mid-season droughts.

Since the 1984/85 crop season, on-farm farmer-managed trials have been conducted on alternative combinations of improved early-maturing varieties, plant densities and chemical fertilisation. The yield coefficients for the improved technologies analysed in this study were computed from 4 years of on-farm trials in the region of study. The yields from traditional cropping systems were computed from 4 years of field data covering the period 1984-1987. Extensive discussion of the yield estimates under different states of rainfall are provided elsewhere (Adesina, 1988, see appendix tables C.1-C.10). The yield distributions allowed the analysis of technology effects for states of nature (rainfall-variation) -prevalent- in Niger $(1965-1985)$. The technologies analysed are: (a) traditional farmer practices; (b) improved early-maturing varieties at higher planting densities; and (c) improved agronomy technology, which includes the utilisation of improved early-maturing varieties combined with higher plant densities and application of chemical fertiliser.

\section{Conceptual framework and methodology}

The methodology applied in this study (Discrete Stochastic Programming) can be used to solve sequential decision problems where the functional, input-output coefficients and/or resource supplies can be represented by discrete probability distributions (Cocks, 1968). The use of the method requires the utilisation of the following steps: specification of all possible actions open to the farmer; random events influencing these decisions; probabilities of the random events; an objective function for the decisionmaker; and an appropriate information structure linking decisions in each stage of the planning horizon. Also, there is a need to specify resource supplies for each state of nature within each stage of the planning horizon. Hence, the matrix size of a realistic DSP model is much larger than its linearprogramming counterpart.

While the approach has been applied to solving empirical problems in

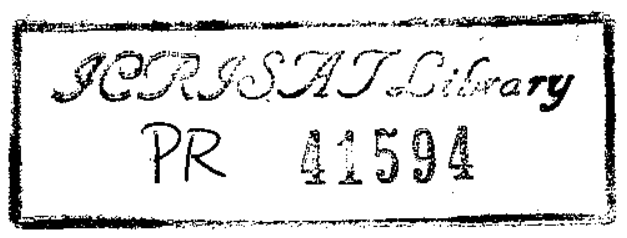


developed agriculture (Rae, 1971; Tice and Clouser, 1982) applications to developing-country agriculture have not received attention. Specifically, no study in Niger has applied this technique to farmer decision-making.

In the empirical model, the following steps were followed. The decision dates at which farmers make planning decisions are divided into three stages (Fig. 1): Stage 1 (May-June); Stage 2 (July-September); Stage 3 (October - March). At the start of the season in stage 1, farmers wait for the arrival of the rains before planting begins. Rains in this stage can be classified as 'early', or 'late'. If rains are 'early', the intensities and levels can vary. Hence 'early' rains can be of two types: 'weak' or 'good'. In general, 'early' rains in the region has been associated with a long growingseason and vice versa (Sivakumar, 1988 p. 301.). In stage 2, rains can continue to be 'good' or 'weak'. Hence the possible states of nature cor-

(May.June)

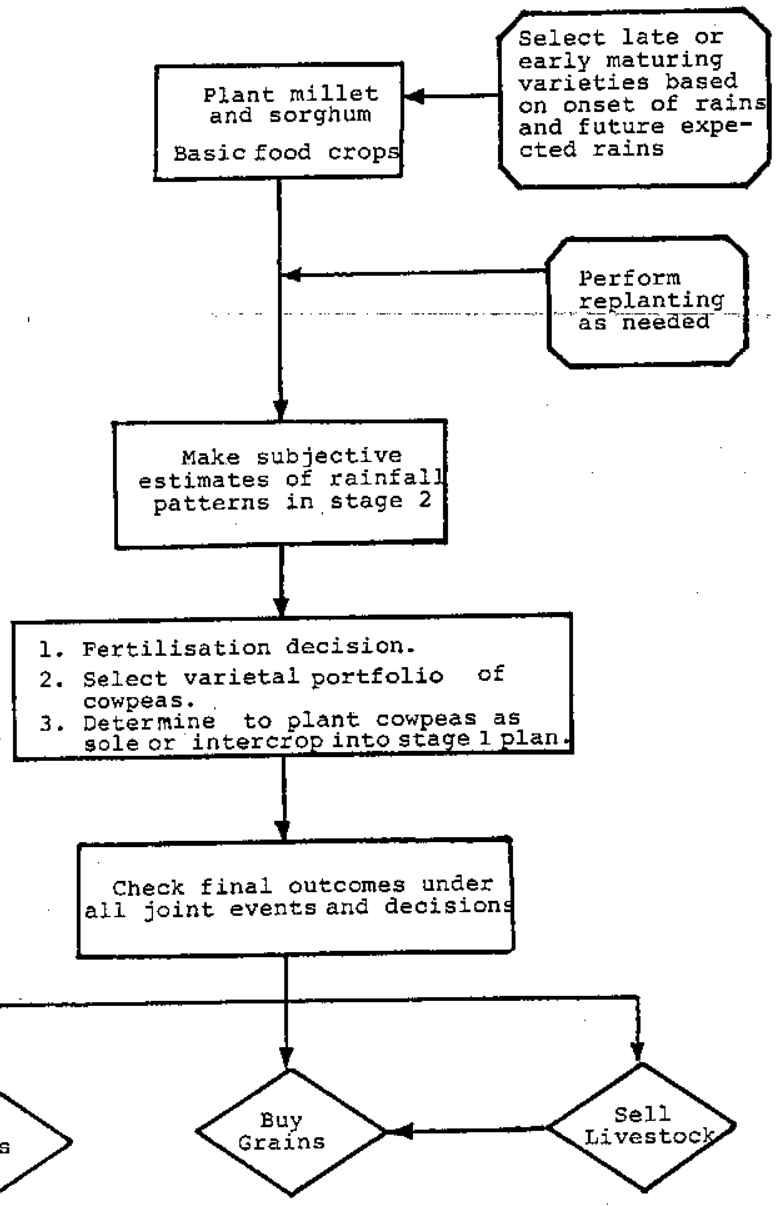

Stage2

(July.sep)

Fig. 1. Schematic diagram of decisions on a typical farm in Sourthern Maradi, Niger. 
respondences in stage 1 and stage 2 are: 'good/good'-classified as very good rainfall year; 'weak/good'-classified as a good rainfall year; 'good/weak' - classified as a normal rainfall year; 'weak/weak' - classified as a poor rainfall year; and 'late/weak' - classified as a very poor rainfall year. The probabilities associated with these states are given in Table 1.

In stage 2, the cropping decisions taken (Fig. 1), which are dependent on weather patterns, are: whether to continue stage 1 crop plans without addition of cowpeas; whether to plant cowpeas, and if so, whether it should be in sole crop or interplanted with cereals selected in stage 1; whether to select early-maturing cowpeas or plant long-season varieties; and, whether to apply chemical fertilisers.

In stage 3, farmers undertake risk-management strategies to cope with resulting crop output (under each of the states of nature sequences) in view of the family's consumption and cash objectives. These decisions involve buying grains in the event of inadequate stocks to meet household consumption objectives. Farmers could also sell livestock to generate liquidity for cereal purchases. These adjustments strategies are common in low-rainfall years and are hence incorporated in the model.

The empirical model is made up of 150 constraints and 200 decision variables. The representative farm is made up of three adults (actifs). Labor is supplied entirely from the household, and there is-no hiring of labor. Average farm size varies from 2 to 4 ha in the zone of study. The representative farm could cultivate up to 3.5 ha depending upon Iabour availability. Cash resources includes 7000 FCFA which can be used to buy seeds, fer-

\section{TABLE 1}

Probabilities of states of nature

\begin{tabular}{lcccccc}
\hline & \multicolumn{2}{l}{ State of nature } & & & \\
\cline { 2 - 6 } & Very good & Good & Normal $^{\text {b }}$ & Poor & Very poor \\
\hline Rainfall (mm/year) & $>594$ & $484-594$ & $350-483$ & $267-349$ & $<267$ \\
Initial probabilities & 0.30 & 0.24 & 0.23 & $0.19^{c}$ & $0.04^{c}$ \\
Probalilities & 0.34 & 0.24 & 0.23 & 0.16 & 0.03 \\
Estimates usedc & & & & & \\
\hline
\end{tabular}

aBased on annual rainfall in Maradi Region of Niger from 1961 to 1985.

${ }^{\mathrm{b}}$ The average annual rainfall in this period was $483 \mathrm{~mm} / \mathrm{year}$.

'Several authors have argued that the recent low rainfall patterns (characterized by 'poor' and 'very poor' states of nature respectively) are a temporary cyclical phenomena (see Bunting et al., 1975). Therefore, the probabilities of these states of nature were adjusted downwards and the estimate for the 'very good' state of nature adjusted upward. 
tilisers, and farm implements. The household has an initial livestock asset of six ruminants, consisting of three rams and three goats. Subsistence cereal requirements can be met from millet and sorghum. Cowpeas are grown for cash. Minimum cereal subsistence requirements are set at $266 \mathrm{~kg}$ per head per year. Consumption needs can be met from domestic production and (or) through direct purchases on the market. Carry-over grain stocks are not considered because these farmers are generally net purchasers of grain.

The model is presented below in matrix notation:

$A_{i 1}=(n \times n)$ matrix of stochastic resource requirements under state $i$ $(i=1,3)$ in stage 1 .

$B_{i 1}=(n \times 1)$ vector of resource supplies for state $i(i=1,3)$ in stage 1 . $A_{i j 2}=(n \times n)$ matrix of resource requirements for activities in stage 2 , when occurrence of state $i$ in stage 1 is followed by occurrence of state $j(j=1,2)$ in stage 2 .

$B_{i j 2}=(n \times 1)$ vector of resource supplies in stage 2 , when occurrence of state $i$ in stage 1 is followed by occurrence of state $j$ in stage 2 .

$\pi_{i j}=$ profits from farm plans selected when rainfall state-of-nature $i$ and $j$ occur in stages 1 and 2, respectively. For example: $\pi_{\mathrm{gg}}$ is the profit in the very good year.

$C_{i I}=(1 \times n)$ vector of net margins for the crop activities initiated in stage 1 under state $i$, and continued through stage 2 without any addition of new crop plans.

$C_{i j 2}=(1 \times n)$ vectors of net margins for the crop activities selected under state $i$ in stage 1 and continued to stage 2 (under state $j$ ), with addition of new crop plans in stage 2 .

$\beta_{i j}=$ probabilities associated with the states-of-nature joint events, where $\Sigma_{i} \Sigma_{j} \beta_{i j}=1$.

$X_{i 1}=(n \times 1)$ vector of decision activities initiated in stage 1 under state of nature $i$.

$X_{i j 2}=(n \times 1)$ vector of decision activities in stage 2 , given the occurrence of states-of-nature $i$ and $j$ in stage 1 and 2, respectively.

$T=$ a matrix for preserving proper sequencing of activities and resource transfers between decision stages and states-of-nature.

$\operatorname{MAX} E(\pi)=\Sigma_{i} \Sigma_{j} \beta_{i j} \pi_{i j}$

subject to:

$A_{i 1} X_{i 1} \leq B_{i 1}$

$A_{i j 2} X_{i j 2} \leq B_{i j 2}$

$-T X_{i 1}+T X_{i j 2} \leq 0$ 
$-C_{i 1} X_{\mathrm{il}}-C_{i j 2} X_{i j 2}+\pi_{i j}=0$

$\pi_{i j}, X_{i j 2}, X_{i 1} \geq 0$

(1) is the objective function and represents a weighted sum of the profits (expected profits) from cropping decisions taken under each of the joint states-of-nature sequences. The associated weights are the probabilities of the respective joint events.

(2) represents input - output coefficients and resource supplies corresponding to activities performed'when 'good', 'weak', and 'late' rains occur in stage 1 . The input - output coefficients are disaggregated for each state-ofnature. Replanting activities are allowed under each state-of-nature. Allowances are also provided for the transfer of fallow land and cereal cropped areas into stage 2 .

(3) represents constraints for activities, input-output coefficients and resource supplies for stage 2 decisions.

(4) represent series of transfer rows which transfers crop activities and resources from stage 1 to stage 2 under the corresponding states-of-nature. The transfer matrices $(T)$ are not identity matrices but have non-zero offdiagonal elements as activities from a specific state-of-nature in stage 1 can be transferred into more than one set of cropping activities in stage 2 . These constraints therefore preserve the proper sequencing of activities and resource transfers. Equation (5) represent expected profits from crop plans selected under the joint events, while (6) represent non-negativity constraints on the decision variables.

\section{Results}

In the states-of-nature characterized by 'poor' and the 'very poor' rainfall, and with farmers only having traditional activity choices available (Table 2), the model predicts that farmers do not plant sorghum. Millet becomes increasingly important in such scenarios. In the very poor years, millet cultivation completely displaces sorghum. This is consistent with observed farmer behavior in recent low rainfall years. Farmers have been observed to adapt to the declining rainfall and decreasing soil fertility by planting millet, which tolerates (better than sorghum) low rainfall and grows on soils with lower fertility. Hence, the model results show the traditional adaptation of farmers to poor rainfall by selection of a crop better-adapted to more-marginal conditions.

With the introduction of early-maturing cultivars (Table 2) the acreage reallocation patterns predict that:

(1) More diversified crop patterns are adopted in the 'very good' year due to the excellent rainfall which supports such production patterns. 


\section{TABLE 2}

Optimal crop plans (ha) with introduction of alternative technologies

State of nature

\begin{tabular}{llll}
\hline $\begin{array}{l}\text { Very } \\
\text { good }\end{array}$ & Good Normal Poor & $\begin{array}{l}\text { Very } \\
\text { poor }\end{array}$ \\
\hline
\end{tabular}

(a) Traditional technology

Local millet sole crop

Local millet/local cowpeas

Local millet/local sorghum/ local cowpeas

Local cowpeas sole crop

$-$

$-\quad-$

0.88

1.53

Local millet/local sorghum

0.92

0.93

0.47

0.88

$-$

(b) Improved variety introduction

Early millet sole crop

Local millet sole crop

Early millet/early cowpea

Local millet/local cowpea

Local millet/local sorghum

Local millet/local sorghum/ local cowpeas

Local millet/local sorghum/ early cowpeas

Early cowpeas sole crop

Local cowpeas sole crop

Local millet/early cowpeas

Early millet/local cowpeas

(c) Improved agronomy introduction

Early millet sole crop

Local millet sole crop

Early millet/early cowpea

Local millet/local cowpea

Local millet/local sorghum

Local millet/local sorghum/ local cowpeas

Local millet/local sorghum/ early cowpeas

0.8

0.8

0.8

$\overline{-} \quad \overline{0} \quad \overline{0}$

0.92

0.93

1.23

$\begin{array}{lllll}- & - & - & 0.88 & 1.53 \\ - & - & - & - & - \\ - & - & - & 0.90 & - \\ - & - & - & - & - \\ 1.05 & 0.93 & 1.09 & - & - \\ 0.7 & 0.93 & - & - & - \\ 0.36 & - & 1.09 & - & - \\ - & - & 0.8 & 0.8 & 0.8 \\ 0.8 & 0.8 & - & - & - \\ - & - & - & - & - \\ - & - & - & - & -\end{array}$

Early cowpeas sole crop

Local cowpeas sole crop

$\begin{array}{lllll}0.37 & 0.72 & 0.72 & 1.12 & 1.53\end{array}$

Local millet/early cowpeas

Early millet/local cowpeas

Early millet/early cowpeas at higher planting density

$\begin{array}{lllll}0.37 & 0.72 & 0.72 & 1.12 & 1.53 \\ - & - & - & - & -\end{array}$

$\begin{array}{llllll}- & - & - & - & -\end{array}$

$\begin{array}{lllll}- & - & - & - & - \\ 0.89 & 0.1 & 0.36 & - & -\end{array}$
and $50 \mathrm{~kg} / \mathrm{ha}$ SSP and $50 \mathrm{~kg} / \mathrm{ha}$ Urea 
(2) In the 'poor' and 'very poor' rainfall situations, farmers change varietal allocations to include early-maturing varieties. In these states-ofnature, the model shows that the early-maturing variety of millet will be planted.

(3) Intercropped early-maturing millet and early-maturing cowpeas were adopted in the 'poor' rainfall years. Moreover, with transition into the 'very poor' rainfall state, the model predicts the optimal decision is to shift away from intercropped millet, into sole cropping of early-maturing millet and cowpeas, respectively. These adoption patterns predicted from the model corroborates with recommendations from experiment stations. Reddy (1988) recommends that, when rainfall is late, farmers appear to be better-off planting early-maturing millet and cowpeas in sole or intercrops.

(4) In each state-of-nature, farmers devoted 0.8 ha to cultivation of cowpeas. It is noteworthy, however, that while local (late-maturing) varieties were used in the 'very good' and 'good' rainfall states, the optimal decisions in the 'normal', 'poor' and 'very poor' rainfall states was cultivation of early-maturing cowpeas.

The implication of the results is that farmers can change their choices of crop varieties by selecting appropriate cultivars to fit the variability in the rainfall patterns. Such a flexible crop-management strategy--will allow farmers to exploit the long growing-seasons in good rainfall years (by planting local late-maturing cultivars), and avoid crop failures in low-rainfall years with short growing-seasons (by cultivating early-maturing cultivars).

The results have strong implications for the orientation of biological research programs in Niger. Some authorities (Lamb, 1983; Nicholson, 1983) have claimed that the Sahelian rainfall patterns are expected to be on a persistent downward trend, and intra-seasonal rainfall will continue to show a declining trend, especially in the peak rainfall month of August which coincides with grain-filling period (Dennett et al. 1985). If this permanent-change hypothesis holds true, then the breeding programs in Niger must strengthen their orientation towards development of earlymaturing cultivars with good drought-tolerance levels. This would allow farmers the flexibilities needed in varietal selection to adapt to ensuing rainfall patterns in the season.

However, the most predominant view is that rainfall cycles follow $15-30$ year periods, and that $1967-1985$ was a low rainfall period in the Sahel just as $1950-1967$ was a high-rainfall period. If this view is correct, and the current low-rainfall pattern is a temporary phenomenon (Bunting et al., 1975), the crop-improvement programs should involve diversification of a portfolio mix of intermediate and long-season varieties with good adaptation traits. The model results show that early-maturing varieties developed are 
TABLE 3

Post-harvest risk management strategies under alternative technologies and weather patterns

Weather states

Very Good Normal Poor Very

good poor

(a) Traditional technology

- Crop sales (kg)

Cereals/farm

Cowpeas/farm

Cereals/actif

Cowpeas/actif

$\begin{array}{rrrrr}149 & - & - & - & - \\ 320 & 253 & 112 & 59 & 16 \\ 50 & - & - & - & - \\ 106 & 84 & 37 & 20 & 5\end{array}$

- Livestock sales (per farm)

Sheep

Goats

- Cereal purchase on market $(\mathrm{kg})$

Per farm

Per actif

$\begin{array}{rrrrr}- & - & 1 & 2 & 3 \\ - & - & - & - & 2 \\ & & & \ddots & \\ - & - & 228 & 579 & 661 \\ - & - & 76 & 193 & 220\end{array}$

(b) Early-maturing varieties

- Crop sales $(\mathrm{kg})$

Cereals/farm

Cowpeas/farm

Cereals/actif

-Cowpeas/actif

$\begin{array}{rrrrr}300 & - & - & - & - \\ 310 & 253 & 214 & 150 & 24 \\ 100 & - & - & - & - \\ 103 & 84 & 71 & 50 & 8\end{array}$

- Livestock sales (per farm)

Sheep

Goats

- Cereal purchase on market $(\mathrm{kg})$

Per farm

Per actif

$$
\begin{array}{rrrrr}
- & - & 1 & 2 & 3 \\
- & - & - & - & 2 \\
- & - & 203 & 536 & 641 \\
- & - & 68 & 179 & 213
\end{array}
$$

(c) Improved agronomy

- Crop sales $(\mathrm{kg})$

Cereals/farm

Cowpeas/farm

Cereals/actif

Cowpeas/actif

$\begin{array}{ccccc}524 & - & - & - & - \\ 308 & 316 & 135 & 95 & 24 \\ 175 & - & - & - & - \\ 103 & 105 & 45 & 32 & 8\end{array}$

- Livestock sales (per farm)

Sheep

Goats

$$
\begin{array}{lllll}
- & - & - & 1 & 3
\end{array}
$$

- Cereal purchase on market $(\mathrm{kg})$

Per farm

- $\quad-\quad$ - 323641

Per actif

- $\quad$ - $\quad-\quad 108 \quad 214$


not always utilised by farmers. The farmer's portfolio mix involves selective utilization of early-maturing and long-season, traditional, low-yielding varieties. The results show that, by carrying such a portfolio, farmers would be able to adjust planting strategies based upon their perceptions of the growing-season rainfall patterns. There needs to be a balance in the allocation of research funds, to cover development of a varietal portfolio mix for farmers. Breeders should do more work on better utilization of local germplasm to develop intermediate and full-season varieties for farmers.

In terms of adoption patterns for the improved agronomy technical package (Table 2), the model predicts that farmers would continue to devote most of their acreage to cropping systems involving no fertilizer utilization. The improved agronomy package was, however, adopted in small areas $(0.4-0.7 \mathrm{ha})$ in four of the five states-of-nature. The technology was not adopted in the very-poor-rainfall scenario. However, the probability of this state is very low - only about $4 \%$ - even though farmers may give it a higher weight due to the recent occurrence of major drought in 1984 .

The expected output (computed across all states-of-nature) shows that, by adopting early-maturing varieties, farmers can expect only a marginal improvement in production of $10 \%$ higher than expected output under traditional technologies. By adopting the improved-agronomy technical package, an expected output increment of $27 \%$ over traditional technology could be obtained.

Post-harvest adjustments in stage 3 to the resulting crop production patterns under each technology and rainfall pattern are shown in Table 3 . The model predicts that, under traditional technology, farmers sell grains only in the very good year. The model predictions of the amount of cereals sold in the very-good rainfall scenario represents $16 \%$ of total millet and sorghum produced. This estimate of marketed cereal output in the base scenario is consistent with observed village-level sales patterns in the region of study. Surveys of farmers' marketing behavior show that grain sales are very low, ranging from $15 \%$ to $17 \%$ of total output in better rainfall years (Berg et al. 1983), and from $0 \%$ to $4 \%$ in drier years (Swinton and Mammane, 1984). In terms of grain purchases in the post-harvest period, model results shows that no grains are bought in the 'very good' and 'good' rainfall years. In the 'normal', 'poor' and 'very poor' rainfall scenarios, the model predicts increased dependency on the market for grain purchases. Livestock was sold in order to meet cash demands for consumption requirements. The amount of livestock sold increased with transition from the higher-rainfall scenarios to the lower-rainfall scenarios in the model results. With the introduction of early-maturing varieties, farmers were able to sell more cowpeas than under traditional technologies. In terms of livestock sales to buy grains, there was no difference compared with traditional technologies. 
TABLE 4

Cereal self-sufficiency index ${ }^{a}$ under alternative technologies

\begin{tabular}{|c|c|c|c|c|c|}
\hline & \multicolumn{5}{|c|}{ State of nature } \\
\hline & Very good & Good & Normal & Poor & Very poor \\
\hline Traditional & 1.0 & 1.0 & 0.72 & 0.28 & 0.17 \\
\hline Improved varieties & 1.0 & 1.0 & 0.75 & 0.33 & 0.20 \\
\hline Improved agronomy & 1.0 & 1.0 & 0.99 & 0.60 & 0.20 \\
\hline
\end{tabular}

a These values represent the amount of cereals (millet and sorghum) produced as a proportion of subsistence requirements. These values range between 0 and 1 . The closer they are to 1 the better is the ability of the farmer to feed his household.

However, slightly lower amounts of millet were bought with the introduction of early-maturing cultivars.

Introduction of the improved agronomy technology leads to an increase in the amounts of grains farmers were able to sell in the very good year. Millet market volume increased from $300 \mathrm{~kg}$ (under improved varieties alone) to $524 \mathrm{~kg}$ under the improved-agronomy package. The amounts of millet bought' in the 'normal' and "poor' states of nature also declined substantially with the adoption of the improved-agronomy package. Similarly, in the 'very poor' state-of-nature, the quantity of millet bought on-the-market-was $323 \mathrm{~kg}$, a big decline from $579 \mathrm{~kg}$ bought with the traditional technology. Most significantly, livestock sales declined by $50 \%$ in the 'normal' and 'poor' rainfall years with the adoption of the improvedagronomy package. This reduction in asset depletion is an important indirect-income effect not directly measured by income changes.

The cereal self-sufficiency indices under each technology are shown in Table 4. In the 'very good' and 'good' rainfall scenarios, farmers were selfsufficient in cereal production. Deficits occurs in the 'normal', 'poor' and 'very poor' rainfall scenarios. Improved agronomy makes farmers selfsufficient in normal years and $60 \%$ self-sufficient in cereals in poor-rainfall years. Neither of the technologies has any effects on the domestic cereal selfsufficiency in the very poor year. Therefore, technical change cannot ameliorate the unfavorable effects of a full-scale drought year, and food aid would have to buffer farmers.

Incomes to investment in agricultural technologies, though higher than returns from traditional farmer technology, are still very low (Table 5). Expected total incomes over all states of rainfall ranges from 53204 FCFA (US\$ 183) under traditional technology to 66172 FCFA (US\$228) under the improved-agronomy technical package. The use of cash incomes, as oppos- 


\section{TABLE 5}

Comparison of expected cash income (FCFA) ${ }^{\mathrm{a}}$ and expected total income over all states of weather for alternative technologies (per farm and per actif)

\begin{tabular}{llll}
\hline & & & \\
\cline { 3 - 4 } & & Technology & \\
\cline { 3 - 4 } & & & $\begin{array}{l}\text { Traditional } \\
\text { Early- } \\
\text { maturing } \\
\text { varieties } \\
\text { agronomy } \\
\text { technical } \\
\text { package }\end{array}$ \\
\hline (a) Expected cash income/farm & 27410 & 32743 & 34642 \\
(b) Expected cash income/actif & $(95)$ & $(113)$ & $(119)$ \\
& 9136 & 10914 & 11547 \\
(c) Expected total income/farm & $(31)$ & $(38)$ & $(40)$ \\
(d) Expected total income/actif & 53204 & 59328 & 66172 \\
& $(183)$ & $(205)$ & $(228)$ \\
& 17734 & 19776 & 25057 \\
& $(61)$ & $(68)$ & $(76)$ \\
\hline
\end{tabular}

a Exchange rate: 290 FCFA $=$ US\$ 1.00 (December 1989). The values in parenthesis are dollar equivalents. The coefficient of variation of expected total income over all states of nature are: $\mathrm{CV}=0.52$ (traditional technology), $\mathrm{CV}=0.44$ (early-maturing varieties) and $\mathrm{cV}=0.42$ (improved agronomy).

ed to total incomes (i.e., with valuation of cereal consumed at home), significantly under-estimates agricultural returns. Returns (total incomes per hour) to labor are also low (Table 6), but are higher than the rural wage rate in most weather states, except the 'very poor' year. It is therefore not surprising that farmers have diversified their income sources outside of agriculture. Incomes from agriculture represent a fraction of farmer's incomes, with seasonal migration, remittances and small-scale trading becoming important in buttressing the low and highly variable incomes from agriculture (Reardon et al., 1988).

One method to increase these low returns to investment in agricultural technologies is to prevent the cereal price collapses normally observed in very good rainfall years. The setting of price floor at $50 \mathrm{FCFA} / \mathrm{kg}$ has two income effects (Table 7) when compared to the situation of price collapse (cereal price $=35 \mathrm{FCFA} / \mathrm{kg}$ ) experienced in years of high rainfall:

(1) Total incomes in the very good year increased by $19 \%$ with use of traditional technologies, by $28 \%$ with the utilisation of improved varieties, and by $43 \%$ with the adoption of the improved agronomy package. Hence, the adoption of improved technologies will allow farmers the options of capturing the income gains from the use of price floors.

(2) With grain prices falling to $35 \mathrm{FCFA} / \mathrm{kg}$ in the very good years, the 
TABLE 6

Cash and total returns (FCFA) to labor per adult equivalent under alternative technologies for five weather patterns

\begin{tabular}{|c|c|c|c|}
\hline State of nature & Technology ${ }^{\mathrm{a}}$ & $\begin{array}{l}\text { Cash incomes/ } \\
\text { hours worked } \\
\text { (FCFA/h) }\end{array}$ & $\begin{array}{l}\text { Total income/ } \\
\text { hours worked } \\
\text { (FCFA/h) }\end{array}$ \\
\hline \multicolumn{4}{|l|}{ Very good } \\
\hline & (1) & 101 & 163 \\
\hline & (2) & 104 & 163 \\
\hline & (3) & 114 & 171 \\
\hline \multicolumn{4}{|l|}{ Good } \\
\hline & (1) & 76 & 143 \\
\hline & (2) & 76 & 143 \\
\hline & (3) & 108 & 185 \\
\hline \multicolumn{4}{|l|}{ Normal } \\
\hline & (1) & 31 & 97 \\
\hline & (2) & 58 & 127 \\
\hline & (3) & 38 & 133 \\
\hline \multicolumn{4}{|l|}{ Poor } \\
\hline & (1) & 36 & 110 \\
\hline & (2) & 48 & 111 \\
\hline & (3) & 32 & 123 \\
\hline \multicolumn{4}{|l|}{ Very poor } \\
\hline & (1) & 10 & 61 \\
\hline & (2) & 15 & 77 \\
\hline & (3) & 15 & 74 \\
\hline
\end{tabular}

a (1), traditional technology; (2), introduction of improved early maturing varieties; (3), introduction of improved agronomy technical package. Rural wage rate $=100 \mathrm{FCFA} / \mathrm{h}$.

inability of the official marketing agency (OPVN) to effect the $70 \mathrm{FCFA} / \mathrm{kg}$ official minimum price floor leads to substantial income losses. These losses increase with the level of marketed output, which in turn depends on the productivities of technologies adopted. For example, the price collapse leads to an estimated income loss of $45 \%$ with use of tranditional technology, $50 \%$ loss with the adoption of improved varieties, and 55\% income loss with the adoption of improved agronomy package.

Implementing an effective price floor presupposes that the official marketing agency has sufficient financial and storage capacities to buy increased marketed output available in years with high rainfall. Unless price floors are effective, the income effects from high-yielding technologies cannot be fully appropriated by farmers. An alternative to a price-support operation is a small-animal feeding program to be promoted and market 


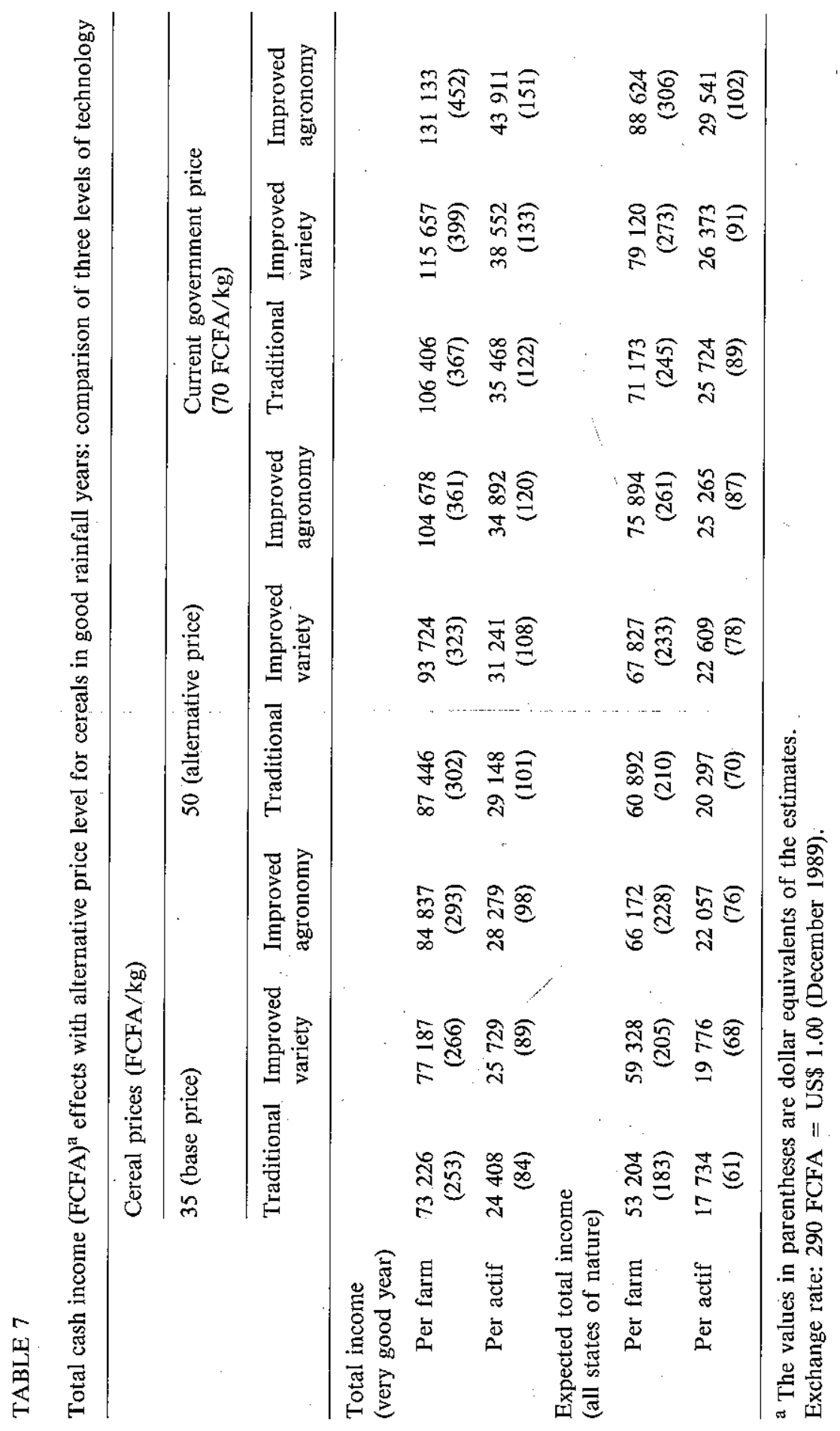


facilitated by the government only in those years when cereals have sufficiently low prices to become feed grains.

\section{Conclusions}

The ability of peasant farmers in Niger to adapt cropping and resourcemanagement strategies to the rainfall patterns is the basis for their survival in this high-risk environment. This paper has shown that by (a) carrying a portfolio mix of varieties of varying maturities, and (b) making sequential decisions based upon rainfall expectations, farmers can adapt to the production uncertainties. There is need for a reorientation of biological research priorities to accommodate these adaptive responses of farmers. Specifically, breeding programs should be diversified to develop not only early-maturing cultivars (which are useful for drought escape and tolerance), but also improved intermediate and long-season varieties.

The challenge facing agricultural development programs in Niger is how to further increase farmer incomes on the predominantly sandy soils. The poor soil fertility and water-retention capacities of these soils will require that attention be given to millet and cowpeas that do better under these conditions than sorghum. It appears from the model results that sole-cropping of early-maturing cowpeas after-millet establishment-offers farmers a good flexibility in their sequential decision-making. In addition, the improvedagronomy technology appears to offer a good potential for increased farmer incomes and food security positions.

While the evaluated technologies have important effects on farmer food security positions, deficits still occurred in the poor and very poor rainfall years. In the medium term, increased utilisation of national and village-level food-security stocks programs would have to be used to cope in such scenarios. However, the long-term solution to the food problem in Niger will need to depend on the generation of appropriate technologies which could perform moderately well in low-rainfall years. It is unlikely that technologies would be found for very poor years.

Finally, the returns to crop production are precariously low for these resource-poor farmers, and show tremendous variabilities across rainfall patterns. This situation is worsened by the inability of the government to prevent cereal price collapse in the higher-rainfall years, when farmers invest in agricultural technologies and have more grain to sell. Agricultural technologies cannot have much effect if there are no assured market outlets and a stable price structure to reduce market uncertainties. It is recommended that the government of Niger put in place effective price floors or smallanimal feeding programs to be activated only in the very-good rainfall years. The setting of an effective price floor is especially crucial for the small 
farmers who must sell a major portion of their grain during or immediately after harvest when prices are at their lowest. However, for the price floor to have an effect on farmer investments in agricultural technology to enhance cereal productivities, it must be announced early in the season and must be at a level high enough to.justify technology investment. This aside, the official grain-marketing agency (OPVN) must be ready to buy all grains offered for sale at these prices, which in itself implies large budgetary commitments. Nonetheless, modelling results show that income losses from price collapses experienced in good rainfall years could be as high as $55 \%$ of expected total incomes. Such erosion of potential incomes cannot sustain the process of cereal technology utilisation for a stable agricultural development in Niger.

\section{Acknowledgements}

The authors thank INTSORMIL PRF-5 for funding the research. Logistic assistance of Institute National de Recherches Agronomique du Niger is acknowledged. Views expressed in the paper should not, however, be construed as reflecting their position. The comments and suggestions of Yemisi Adesina, Tim Baker, Paul Preckel, Emmanuel Nzewi and Barry Shapiro during various stages of this research are-acknowledged. An earlier version of the paper was presented at the Ninth International Farming Systems Research and Extension Symposium, Fayetteville Arkansas, U.S.A. 8-11 October 1989.

\section{References}

Adesina, A.A., 1988. Farmer behavior and new agricultural technologies in the rainfed agriculture of Southern Niger: a stochastic programming analysis. Ph.D. thesis, Purdue University, West Lafayette, IN, $138 \mathrm{pp}$.

Adesina, A.A., Abbott, P.C. and Sanders J.H., 1988. Ex-ante risk programming appraisal of new agricultural technology: Experiment station fertiliser recommendations in Southern Niger. Agric. Syst., 27: 23-34.

Balcet, J. and Candler, W., 1981. Farm technology adoption in Northern Nigeria. Dep. West-Africa Projects, World Bank, Washington, DC.

Bunting, A.H., Dennett, M.D., Elston, J. and Milford, J.R., 1975. Seasonal rainfall forecasting in West-Africa. Nature, 253: 622.

Cocks, K.D., 1968. Discrete stochastic programming. Manag. Sci., 15: $72-79$.

Dennett, M.D., Elston, J. and Rogers, J.A., 1985. A reappraisal of rainfall trends in the Sahel. J. Climatol., 5: 353-361.

Elliot Berg Associates, 1983. Joint program assessment of grain marketing in Niger. A report submitted to the Government of Niger and the U.S. Agency for International Development. Vol. I; Main Report.

Jaeger, W.K., 1984. Agricultural mechanization: the economics of animal traction in Burkina-Faso. Ph.D. thesis, Stanford University, Stanford, CA. 
Kristjanson, P.M., 1987. The role of information and flexibility in small farm decision making and risk management: evidence from the West-African semi-arid tropics. Ph.D. thesis, University of Wisconsin, Madison, WI.

Lamb, P.J., 1983. Sub-Saharan rainfall update for 1982: continued drought. J. Climatol., 3: 419.

Matlon, P.J., 1987. Prospects for improving the productivities of sorghum and pearl millet in West-Africa. Paper presented at the Conference on the Dynamics of Cereal Consumption and Production Patterns in West-Africa, 15-17 July, Dakar, Senegal.

Nagy, J.G., Sanders, J.H. and Ohm, H.W., 1988. Cereal technology interventions for the West African semi-arid tropics. Agric. Econ., 2: 197-208.

Niang, A., 1980. A linear programming model of a representative Sahelian farm: the cases of cotton zone in Mali and the peanut zone in Senegal. Ph.D. thesis, Purdue University, West Lafayette, IN.

Nicholson, S.E., 1983. Sub-Saharan rainfall in the years 1976-1980: evidence of continued drought. Mon. Weather Rev., 111: 1647.

Norman, D.W., Newman, M.D. and Ouedraogo, I., 1981. Farm level and village level production systems in the semi-arid tropics of West Africa: an interpretive review of research. ICRISAT Res. Bull. 4 (1), International Crops Research Institute for the Semi-Arid Tropics, Patancheru, India, $100 \mathrm{pp}$.

Rae, A.N., 1971. An empirical application and evaluation of discrete stochastic programming in farm management. Am. J. Agric. Econ., 53: 625-638.

Reardon, T., Matlon, P.J. and Delgado, C., 1988. Coping with household food security in the drought affected areas of Burkina-Faso. World Dev., 16: 1065-1074.

Reddy, K.C., 1988. Strategies alternatives pour la production de Mil-Niebe pendant L'hivernage. Fascicule 1, Institut National -de Recherches Agronomique du Niger.

Sanders, J.H., 1989. Agricultural research and cereal technology introduction in BurkinaFaso and Niger. Agric. Syst., 30: 139-154.

Sivakumar, M.V.K., 1988. Predicting rainy- season potential from the onset of rains in the -Southern-Sahelian and Sudanian climatic zone of West-Africa. Agric. For. Meteorol., 42: $295-305$.

Spencer, D.S., 1985. A research strategy to develop appropriate agricultural technologies for small farmer development in sub-Saharan Africa. In: H.W. Ohm and J.G. Nagy (Editors), Appropriate Technologies for Small Farmers in Semi-Arid West Africa. International Programs in Agriculture, Purdue University, West Lafayette, IN, pp. 308-325.

Starkey, P., 1986. Animal drawn wheel tool carriers: Perfected yet rejected. Viewweg, Braunschweig/Wiesbaden, Fed. Rep. Germany, 161 pp.

Swinton, S.M., 1988. Drought survival tactics of subsistence farmers in Niger. Human Ecol., 16: $123-144$.

Swinton, S.M. and Mammane, A., 1986. Les Exploitations Agricoles dans trois Villages de Madarounfa face à la Sercheresse de 1984 et 1985. Doc. 15 F, DECOR, Institut National de Recherches Agronomique du Niger.

Tice, T.F. and Clouser, R.L., 1982. Determination of the value of weather information to individual crop producers. J. Appl. Metereol., 21: 447-452.

Unité Suivi d'Evaluation, 1986. Les systèmes de culture an sud du Departement de Maradi: Analyse des pratiques culturales et leurs influence sur les rendements. Projet de Developpement Rural de Maradi, Niger. 